\title{
CHINA-US BORDER EFFECT OF AGRICULTURAL TRADE USING GRAVITY MODEL
}

\author{
Haixia Zhu ${ }^{1,2, *}$, Haiying $\mathrm{Gu}^{1}$ \\ ${ }^{1}$ Antai School of Economics and Management, Shanghai Jiao Tong University, Shanghai, P. \\ R. China 200052 \\ 2 School of Foreign Languages, Shanghai Maritime University, Shanghai, P. R. China \\ 200135 \\ Corresponding author, Address: School of Foreign Languages, Shanghai Maritime \\ University, Shanghai, P. R. China 200135, Tel: +86-21-58855200, Fax: +86-21-58854605, \\ Email: haixiazhu@126.com
}

Abstract: Two border effect models capturing the characteristics of agricultural trade based on the Gravity Model are put forward to make a study on China-US border effects in the sector of agricultural trade. Different methods are used to check the robustness of the models. Applying the panel data covering 19872005, the empirical results show that the border effects of China-US exist with a great magnitude and tend to drop over time. They differ greatly from the direction of the international trade. Linear model in log-form can well explain the border effects of China-US agricultural trade.

Keywords: $\quad$ border effect, Gravity Model, China-US, agricultural trade

\section{INTRODUCTION}

The Gravity Model has been widely and successfully used to explain international trade flows for several decades. In particular, the literature on the effects of national borders on trade has adopted this model for investigating the relative volumes of internal versus external trade. The term "border effect" or "home bias" refers to the extent to which volume of domestic trade exceeds the volume of international trade. In other words,

Please use the following format when citing this chapter:

Zhu, H. and Gu, H., 2009, in IFIP International Federation for Information Processing, Volume 294, Computer and Computing Technologies in Agriculture II, Volume 2, eds. D. Li, Z. Chunjiang, (Boston: Springer), pp. 891-900. 
two different countries trade much less with each other than do two regions within one country, taking into account income, size and distance. Many economists believe that national borders represent large and mostly unidentified barrier to trade and reveal existence. Since the study of McCallum (1995) where it was found that inter-provincial trade in Canada is 22 times as large as Canada's international trade with United States, there has been growing research effort done to measure and understand trade border effect in order to achieve world or regional integration.

There are two main ways used so far in the vast empirical studies for estimation of border effect using the Gravity Model. The first one calculates it by comparing intra-national and international trade data, as have been done by McCallum. Another sort of border effect literature instead of measuring tries to explain why national borders have so significant trade deterring effect and to find out whether there are any policy instruments to influence them (Evans, 2003).

However, agricultural trade liberalization has lagged far behind even though agricultural trade plays a crucial role in the total merchandise international trade. Some have paid attention to border effect of agricultural trade and made conclusion that border effect of agricultural trade is also significantly large among developed countries (Furtan \& van Melle, 2004; Olper \& Raimondi, 2005; Paiva, 2005). Besides, the border effect studies have been focusing more on advanced developed countries or regions than on developing countries. Thus this paper tries to study China-US (two world major agricultural countries) border effect of agricultural trade from different approaches based on the Gravity Model.

\section{MODEL SPECIFICATION}

This paper mainly deals with the agricultural products, so more variables with specific importance for agricultural activity need to be included among the main explanatory variables in the basic model used by McCallum (1995): each region's share of agricultural product in GDP and rural population density. In the specification used here, a country's imports of agricultural products from a partner country depends on the size of the countries' respective economies, their land areas, the physical distance between and several dummy variables capturing agricultural characteristics. Thus the equation estimated in $\log$ form has the following specification:

$$
\begin{aligned}
X_{i j t}=\alpha & +\beta_{1} Y_{i t}+\beta_{2} Y_{j t}+\sigma D_{i j}+\beta_{3} y_{i t}+\beta_{4} y_{j t} \\
& +\beta_{5} S A Y_{i t}+\beta_{6} S A Y_{j t}+\beta_{7} \text { land }_{i t}+\beta_{8} \text { land }_{j t} \\
& +\beta_{9} \text { den }_{i t}+\beta_{10} \text { den }_{j t}+\delta \mathrm{B}_{i j t}+\mu_{i j t}
\end{aligned}
$$

where the gravity equation is estimated in log-near form. Adopting standard notation, the independent variable Xijt denotes the real US dollar 
amount of agricultural products imported from $i$ to $j$ in year $t$. Yit and Yjt are the total agricultural products of importer $i$ and exporter $\mathrm{j}$ respectively. Dij is the economic distance between importer and exporter. yit and yjt are the region's real per capita agricultural GDP in year t. SAYit and SAYjt indicate the importer's share of agriculture in GDP in year t. landit and landjt denote the farm land area of importer and exporter. denit and denjt are rural population density of importer and exporter. Bijt is the dummy variable at in year $t$, taking the value of 1 for inter-provincial trade, 0 otherwise and uij is the standard classical error term.

However, equation (1) can't reflect the real bilateral trade flow between each Chinese province and US state since it ignores the direction of the trade. So the dummy is further divided into BEijt and Blijt to denote Chinese agricultural export to US and its agricultural import from US respectively:

$$
\begin{aligned}
X_{i j t}=\alpha & +\beta_{1} Y_{i t}+\beta_{2} Y_{j t}+\sigma D_{i j}+\beta_{3} y_{i t}+\beta_{4} y_{j t} \\
& +\beta_{5} S A Y_{i t}+\beta_{6} S A Y_{j t}+\beta_{7} \text { land }_{i t}+\beta_{8} \text { land }_{j t} \\
& +\beta_{9} \text { den }_{i t}+\beta_{10} \text { den }_{j t}+\delta_{1} \mathrm{BE}_{i j t}+\delta_{2} \mathrm{Bf}_{i j t}+\mu_{i j t}
\end{aligned}
$$

\section{EMPIRICAL STUDY}

The estimation was done through ordinary least squares to explore the magnitude of China-US border effect in the field of agricultural trade. Different methods are used to make a comparatively comprehensive study on this issue by estimating equation (1) and (2) respectively with six methods: method (1) just makes regular regression of the models; method (2) uses $Y_{i}+Y_{j}$ as the weight in the regression to check the heteroscedasticity of the models; method (3) used GDP and per capita GDP to replace total agricultural product and total agricultural product per capita as some scholars did in their study of agricultural trade; methods (4) and (5) respectively challenge the two main ways to calculate the key distance variable of the model-Wei (1996) and Nitsch (2000) \& Leamer (1997) (short as NL method); the last method adds the square of distance to the basic specification to check the nonlinear effects of distance on agricultural trade.

\subsection{Data}

This paper tries to investigate the bilateral trade between China and US every 5 year from 1987 to 2005 . Agricultural products are defined according to HS classification in accordance with Monthly Statistical Report of Chinese Agricultural Import and Export. In order to learn the trade pattern between them, first, each country is divided into different regions according to the geographical places and economic development: China is divided into 
eight regions, namely Northeast region, Beijing \& Tianjin, East Coast, South Coast, Middle China, Southwest region, Northwest region and North Coast according to the book entitled "Multi-Regional Input-Output Model for China" (2005). Because of the great differences in Chinese development before 1995, China is divided into seven regions (Shicunzhenyi \& Wang, 2007). Likewise, U.S. is divided into nine regions according to US Census Bureau, namely New England, Middle Atlantic, East North Central, West North Central, South Atlantic, East South Central, West South Central, Mountain region and Pacific region.

The data for each Chinese region including total agricultural product, population, GDP and land area are taken from the Bureau of Statistics of China, China Yearbook of Statistics, each province's Statistical Yearbook, statistical websites, agricultural websites and Yearbook of Chinese Cities' Statistics. Each region's land area is taken from Chinese Resources and Environment Database and each province's statistical website. The data for each US state are from the 2007 Statistical Abstract-National Data Book, state fact express of US Census Bureau. Bilateral trade data is taken from the Office of Trade and Industry Information, Manufacturing and Services, International Trade Administration of US Department of Commerce, and FAO. The bilateral trade data between each Chinese region is taken from the I-O table provided by the National Center of Information (2005). As no data on bilateral trade flows between Chinese provinces and US states, it is necessary to proceed to some adjustments to reconcile the model with the degree of aggregation of the available trade data.

Distance variable plays an important role in the model, and any error in data processing can bias the last regression result, so this paper applies Head \& Mayer (2000)'s method in dealing with both international and intranational distances. We use the Great Circle Formula to calculate the economic distances between each pair of regions using the population of each region's provincial capitals as the weight.

\subsection{Results and discussion}

In the estimation of China-US border effects, four questions are to be answered: How big were border effects between China and US in agricultural trade? How did these border effects change over time? To what extent did the Chinese import from US differ from its export to US? How did the independent variables influence the dependent variable?

\subsubsection{The analysis of different variables}

The regression results of equation (1) in different sample years are shown in Table1.-Table 5. with standard errors in the parentheses and summarized afterwards. Each model for each method includes 836 observations in total. 
Table 1. Regression results of equation (1)- 1987

\begin{tabular}{|c|c|c|c|c|c|c|}
\hline & (1) & (2) & (3) & (4) & (5) & (6) \\
\hline \multirow[b]{2}{*}{$\alpha$} & -15.028 & -12.820 & -17.358 & -15.916 & -24.520 & -15.028 \\
\hline & $(0.176)$ & $(0.254)$ & $(0.084)$ & $(0.774)$ & $(0.603)$ & $(0.176)$ \\
\hline \multirow{2}{*}{$Y_{i t}$} & 0.966 & 0.793 & 1.043 & 0.966 & 1.022 & 0.966 \\
\hline & $(0.482)$ & $(0.492)$ & $(0.481)$ & $(0.482)$ & $(0.481)$ & $(0.482)$ \\
\hline \multirow{2}{*}{$Y_{j t}$} & 1.263 & 1.146 & 1.352 & 1.263 & 1.326 & 1.263 \\
\hline & $(0.482)$ & $(0.493)$ & $(0.481)$ & $(0.482)$ & $(0.481)$ & $(0.482)$ \\
\hline \multirow{2}{*}{$D_{i j}$} & -0.831 & -0.920 & -0.770 & -0.831 & -0.442 & -0.415 \\
\hline & $(0.710)$ & $(0.691)$ & $(0.704)$ & $(0.710)$ & $(0.935)$ & $(0.355)$ \\
\hline \multirow[b]{2}{*}{$y_{i t}$} & 0.898 & 0.741 & 1.065 & 0.898 & 1.135 & 0.898 \\
\hline & $(0.683)$ & $(0.675)$ & $(0.671)$ & $(0.683)$ & $(0.747)$ & $(0.683)$ \\
\hline \multirow[b]{2}{*}{$y_{j t}$} & 2.083 & 1.886 & 2.237 & 2.083 & 2.376 & 2.083 \\
\hline & $(0.687)$ & $(0.679)$ & $(0.675)$ & $(0.687)$ & $(0.765)$ & $(0.687)$ \\
\hline \multirow{2}{*}{$S A Y_{i t}$} & -0.547 & -0.539 & 1.373 & -0.547 & -0.687 & -0.547 \\
\hline & $(0.787)$ & $(0.788)$ & $(0.779)$ & $(0.787)$ & $(0.805)$ & $(0.787)$ \\
\hline \multirow{2}{*}{$S A Y_{j t}$} & 1.209 & 1.238 & 2.178 & 1.209 & 1.342 & 1.209 \\
\hline & $(0.787)$ & $(0.787)$ & $(0.783)$ & $(0.787)$ & $(0.804)$ & $(0.787)$ \\
\hline \multirow{2}{*}{ land $_{i t}$} & -0.314 & 0.384 & 0.277 & 0.314 & 0.275 & -0.314 \\
\hline & $(0.407)$ & $(0.408)$ & (0.404) & $(0.407)$ & $(0.410)$ & $(0.407)$ \\
\hline \multirow{2}{*}{$\operatorname{land}_{j t}$} & -0.207 & -0.126 & -0.247 & -0.207 & -0.227 & -0.207 \\
\hline & $(0.406)$ & $(0.408)$ & $(0.404)$ & $(0.406)$ & (0.409) & $(0.406)$ \\
\hline \multirow{2}{*}{$d e n_{i t}$} & -0.054 & -0.254 & -0.025 & -0.054 & -0.173 & -0.054 \\
\hline & $(0.783)$ & $(0.772)$ & $(0.775)$ & $(0.783)$ & $(0.793)$ & $(0.783)$ \\
\hline \multirow{2}{*}{$d e n_{j t}$} & -0.163 & -0.343 & -0.133 & -0.163 & -0.260 & -0.163 \\
\hline & $(0.782)$ & $(0.771)$ & $(0.775)$ & $(0.782)$ & $(0.790)$ & $(0.782)$ \\
\hline \multirow{2}{*}{$B_{i j t}$} & -4.470 & -4.395 & -5.074 & -3.582 & -7.569 & -4.470 \\
\hline & $(0.391)$ & $(0.393)$ & $(0.906)$ & $(0.084)$ & $(0.508)$ & $(0.391)$ \\
\hline $\mathrm{R}^{2}$ & 0.515 & 0.538 & 0.524 & 0.515 & 0.511 & 0.515 \\
\hline D.W. & 1.032 & 1.006 & 1.037 & 1.032 & 1.022 & 1.032 \\
\hline
\end{tabular}

Table 2. Regression results of equation (1)- 1992

\begin{tabular}{|c|c|c|c|c|c|c|}
\hline & (1) & (2) & (3) & (4) & $(5)$ & $(6)$ \\
\hline \multirow[b]{2}{*}{$\alpha$} & -12.611 & -12.027 & -13.283 & -12.680 & -17.449 & -12.611 \\
\hline & $(0.666)$ & $(0.752)$ & $(0.825)$ & $(0.522)$ & $(0.148)$ & $(0.666)$ \\
\hline \multirow{2}{*}{$Y_{i t}$} & 1.353 & 1.216 & 1.402 & 1.353 & 1.376 & 1.353 \\
\hline & $(0.437)$ & $(0.450)$ & $(0.447)$ & $(0.437)$ & $(0.431)$ & $(0.437)$ \\
\hline \multirow{2}{*}{$Y_{j t}$} & 1.114 & 1.051 & 1.168 & 1.114 & 1.120 & 1.114 \\
\hline & $(0.436)$ & $(0.449)$ & $(0.446)$ & $(0.436)$ & $(0.431)$ & $(0.436)$ \\
\hline \multirow{2}{*}{$D_{i j}$} & -0.148 & -0.197 & -0.078 & -0.148 & -1.295 & -0.074 \\
\hline & $(0.631)$ & $(0.616)$ & $(0.638)$ & $(0.631)$ & $(0.812)$ & $(0.316)$ \\
\hline \multirow{3}{*}{$y_{i t}$} & 2.117 & 2.019 & 2.090 & 2.117 & 2.484 & 2.117 \\
\hline & $(0.557)$ & $(0.556)$ & $(0.565)$ & $(0.557)$ & $(0.595)$ & $(0.557)$ \\
\hline & 2.203 & 2.092 & 2.185 & 2.203 & 2.617 & 2.203 \\
\hline$y_{j t}$ & $(0.559)$ & $(0.558)$ & $(0.568)$ & $(0.559)$ & $(0.605)$ & $(0.559)$ \\
\hline \multirow{2}{*}{$S A Y_{i t}$} & -1.410 & -1.460 & 2.040 & -1.410 & -1.606 & -1.410 \\
\hline & $(0.709)$ & $(0.714)$ & $(0.704)$ & $(0.709)$ & $(0.713)$ & $(0.709)$ \\
\hline \multirow{2}{*}{$S A Y_{j t}$} & 1.625 & 1.690 & 1.687 & 1.625 & 1.807 & 1.625 \\
\hline & $(0.709)$ & $(0.714)$ & $(0.706)$ & $(0.709)$ & $(0.711)$ & $(0.709)$ \\
\hline \multirow{2}{*}{ land $_{i t}$} & -0.145 & -0.092 & -0.089 & -0.145 & -0.195 & -0.145 \\
\hline & $(0.348)$ & $(0.351)$ & $(0.348)$ & $(0.348)$ & $(0.346)$ & $(0.348)$ \\
\hline \multirow{2}{*}{$\operatorname{land}_{j t}$} & 0.236 & 0.285 & 0.286 & 0.236 & 0.228 & 0.236 \\
\hline & $(0.347)$ & $(0.350)$ & $(0.347)$ & $(0.347)$ & $(0.345)$ & $(0.347)$ \\
\hline \multirow{2}{*}{$d e n_{i t}$} & -0.096 & -0.244 & -0.050 & -0.096 & -0.295 & -0.096 \\
\hline & $(0.692)$ & $(0.688)$ & $(0.697)$ & $(0.692)$ & $(0.694)$ & $(0.692)$ \\
\hline \multirow{2}{*}{$d e n_{j t}$} & -0.420 & -0.563 & -0.375 & -0.420 & -0.605 & -0.420 \\
\hline & $(0.691)$ & $(0.687)$ & $(0.697)$ & $(0.691)$ & $(0.693)$ & $(0.691)$ \\
\hline \multirow{2}{*}{$B_{i j t}$} & -3.910 & -3.949 & -3.970 & -3.831 & -5.735 & -3.910 \\
\hline & $(0.882)$ & $(0.889)$ & $(0.906)$ & $(0.084)$ & $(0.280)$ & $(0882)$ \\
\hline $\mathrm{R}^{2}$ & 0.612 & 0.625 & 0.607 & 0.612 & 0.618 & 0.612 \\
\hline D.W. & 1.310 & 1.348 & 1.268 & 1.368 & 1.468 & 1.310 \\
\hline
\end{tabular}


Table 3. Regression results of equation (1)- 1997

\begin{tabular}{|c|c|c|c|c|c|c|}
\hline & (1) & (2) & (3) & (4) & (5) & (6) \\
\hline \multirow[b]{2}{*}{$\alpha$} & -12.045 & -11.167 & -13.089 & -12.358 & -19.727 & -12.045 \\
\hline & $(0.043)$ & $(0.096)$ & $(0.413)$ & $(0.875)$ & $(0.037)$ & $(0.043)$ \\
\hline \multirow{2}{*}{$Y_{i t}$} & 0.983 & 0.974 & 0.981 & 0.983 & 1.002 & 0.983 \\
\hline & $(0.349)$ & $(0.353)$ & $(0.353)$ & $(0.349)$ & $(0.348)$ & $(0.349)$ \\
\hline \multirow[b]{2}{*}{$Y_{j t}$} & 0.933 & 0.941 & 0.975 & 0.933 & 0.952 & 0.933 \\
\hline & $(0.349)$ & $(0.353)$ & $(0.352)$ & $(0.349)$ & $(0.348)$ & (0.349) \\
\hline \multirow{2}{*}{$D_{i j}$} & -0.503 & -0.539 & -0.455 & -0.503 & -0.963 & -0.251 \\
\hline & $(0.575)$ & $(0.578)$ & $(0.576)$ & $(0.575)$ & $(0.732)$ & $(0.287)$ \\
\hline \multirow{2}{*}{$y_{i t}$} & 2.455 & 2.160 & 2.496 & 2.455 & 2.847 & 2.455 \\
\hline & $(0.486)$ & $(0.486)$ & $(0.491)$ & $(0.486)$ & $(0.539)$ & $(0.486)$ \\
\hline \multirow[b]{2}{*}{$y_{j t}$} & 2.108 & 1.871 & 2.184 & 2.108 & 2.499 & 2.108 \\
\hline & $(0.486)$ & $(0.486)$ & $(0.491)$ & $(0.486)$ & $(0.539)$ & $(0.486)$ \\
\hline \multirow{2}{*}{$S A Y_{i t}$} & -0.215 & -0.341 & 3.194 & -0.215 & -0.551 & -0.215 \\
\hline & $(0.629)$ & $(0.625)$ & $(0.661)$ & $(0.629)$ & $(0.663)$ & $(0.629)$ \\
\hline \multirow{2}{*}{$S A Y_{j t}$} & 0.939 & 1.009 & 2.142 & 0.939 & 1.275 & 0.939 \\
\hline & $(0.629)$ & $(0.625)$ & $(0.663)$ & $(0.629)$ & $(0.663)$ & (0.629) \\
\hline \multirow{2}{*}{ land $_{i t}$} & -0.861 & -0.749 & -0.807 & -0.861 & -0.836 & -0.861 \\
\hline & $(0.340)$ & $(0.339)$ & $(0.338)$ & $(0.340)$ & $(0.339)$ & $(0.340)$ \\
\hline \multirow{2}{*}{$\operatorname{land}_{j t}$} & -0.039 & 0.037 & -0.031 & -0.039 & -0.014 & -0.039 \\
\hline & $(0.340)$ & $(0.339)$ & $(0.340)$ & $(0.340)$ & $(0.339)$ & $(0.340)$ \\
\hline \multirow{2}{*}{$d e n_{i t}$} & -0.725 & -0.729 & -0.760 & -0.725 & -0.879 & -0.725 \\
\hline & $(0.550)$ & $(0.548)$ & $(0.549)$ & $(0.550)$ & $(0.549)$ & $(0.550)$ \\
\hline \multirow{2}{*}{$d e n_{j t}$} & -0.509 & -0.580 & -0.545 & -0.509 & -0.663 & -0.509 \\
\hline & $(0.550)$ & $(0.548)$ & $(0.550)$ & $(0.550)$ & $(0.549)$ & $(0.550)$ \\
\hline \multirow{2}{*}{$B_{i j t}$} & -3.110 & -3.140 & -3.308 & -2.797 & -5.651 & -3.110 \\
\hline & $(0.103)$ & $(0.104)$ & $(0.117)$ & $(0.366)$ & $(0.669)$ & $(0.103)$ \\
\hline $\mathrm{R}^{2}$ & 0.605 & 0.641 & 0.605 & 0.605 & 0.607 & 0.605 \\
\hline D.W. & 1.032 & 1.289 & 1.149 & 1.148 & 1.258 & 1.032 \\
\hline
\end{tabular}

Table 4. Regression results of equation (1)- 2002

\begin{tabular}{|c|c|c|c|c|c|c|}
\hline & (1) & (2) & (3) & (4) & (5) & (6) \\
\hline \multirow[b]{2}{*}{$\alpha$} & -8.237 & -7.688 & -7.902 & -8.323 & -12.436 & -8.237 \\
\hline & $(0.684)$ & $(0.708)$ & $(0.718)$ & $(0.583)$ & $(0.185)$ & $(0.684)$ \\
\hline \multirow{2}{*}{$Y_{i t}$} & 0.881 & 0.895 & 0.833 & 0.881 & 0.920 & 0.881 \\
\hline & $(0.361)$ & $(0.367)$ & $(0.365)$ & $(0.361)$ & $(0.359)$ & $(0.361)$ \\
\hline \multirow{2}{*}{$Y_{j t}$} & 0.859 & 0.873 & 0.817 & 0.859 & 0.898 & 0.859 \\
\hline & $(0.361)$ & $(0.367)$ & $(0.364)$ & $(0.361)$ & $(0.359)$ & $(0.361)$ \\
\hline \multirow{2}{*}{$D_{i j}$} & -0.247 & -0.276 & -0.267 & -0.247 & -1.180 & -0.124 \\
\hline & $(0.584)$ & $(0.587)$ & $(0.589)$ & $(0.584)$ & $(0.732)$ & $(0.292)$ \\
\hline \multirow[b]{2}{*}{$y_{i t}$} & 2.585 & 2.254 & 2.546 & 2.585 & 2.969 & 2.585 \\
\hline & $(0.462)$ & $(0.460)$ & $(0.474)$ & $(0.462)$ & $(0.503)$ & $(0.462)$ \\
\hline \multirow[b]{2}{*}{$y_{j t}$} & 1.966 & 1.705 & 1.894 & 1.966 & 2.350 & 1.966 \\
\hline & $(0.462)$ & $(0.460)$ & $(0.685)$ & $(0.462)$ & $(0.503)$ & $(0.462)$ \\
\hline \multirow{2}{*}{$S A Y_{i t}$} & -0.770 & -0.895 & 2.655 & -0.770 & -1.078 & -0.770 \\
\hline & $(0.592)$ & $(0.587)$ & $(0.685)$ & $(0.592)$ & $(0.614)$ & $(0.592)$ \\
\hline \multirow{2}{*}{$S A Y_{j t}$} & 0.903 & 0.970 & 1.891 & 0.903 & 1.211 & 0.903 \\
\hline & $(0.592)$ & $(0.587)$ & $(0.686)$ & $(0.592)$ & $(0.614)$ & $(0.592)$ \\
\hline \multirow{2}{*}{ land $_{i t}$} & -0.529 & -0.418 & -0.490 & -0.529 & -0.517 & -0.529 \\
\hline & $(0.332)$ & $(0.331)$ & $(0.328)$ & $(0.332)$ & $(0.330)$ & $(0.332)$ \\
\hline \multirow{2}{*}{$\operatorname{land}_{j t}$} & 0.053 & 0.121 & 0.070 & 0.053 & 0.065 & 0.053 \\
\hline & $(0.332)$ & $(0.331)$ & $(0.329)$ & $(0.332)$ & $(0.330)$ & $(0.332)$ \\
\hline \multirow{2}{*}{$d e n_{i t}$} & -0.741 & -0.696 & -0.777 & -0.741 & -0.908 & -0.741 \\
\hline & $(0.582)$ & $(0.582)$ & $(0.588)$ & $(0.582)$ & $(0.579)$ & $(0.582)$ \\
\hline \multirow{2}{*}{$d e n_{j t}$} & -0.550 & -0.567 & -0.582 & -0.550 & -0.716 & -0.550 \\
\hline & $(0.582)$ & $(0.582)$ & $(0.588)$ & $(0.582)$ & $(0.579)$ & $(0.582)$ \\
\hline \multirow{2}{*}{$B_{i j t}$} & -2.321 & -2.308 & -2.094 & -2.234 & -3.738 & -2.321 \\
\hline & $(0.564)$ & $(0.566)$ & $(0.557)$ & $(0.723)$ & $(0.866)$ & $(0.564)$ \\
\hline $\mathrm{R}^{2}$ & 0.618 & 0.651 & 0.612 & 0.618 & 0.623 & 0.618 \\
\hline D.W. & 1.022 & 1.381 & 1.138 & 1.382 & 1.378 & 1.022 \\
\hline
\end{tabular}


Table 5. Regression results of equation (1)- 2005

\begin{tabular}{|c|c|c|c|c|c|c|}
\hline & (1) & (2) & (3) & (4) & (5) & (6) \\
\hline \multirow[b]{2}{*}{$\alpha$} & -10.105 & -10.095 & -10.554 & -10.129 & -12.149 & -10.105 \\
\hline & $(0.056)$ & $(0.101)$ & $(0.117)$ & $(0.998)$ & $(0.186)$ & $(0.056)$ \\
\hline \multirow{2}{*}{$Y_{i t}$} & 1.493 & 1.480 & 1.532 & 1.493 & 1.418 & 1.493 \\
\hline & $(0.232)$ & $(0.238)$ & $(0.321)$ & $(0.232)$ & $(0.231)$ & $(0.232)$ \\
\hline \multirow{2}{*}{$Y_{j t}$} & 1.315 & 1.375 & 1.289 & 1.315 & 1.334 & 1.315 \\
\hline & $(0.307)$ & $(0.311)$ & $(0.320)$ & $(0.307)$ & $(0.303)$ & $(0.307)$ \\
\hline \multirow{2}{*}{$D_{i j}$} & -0.117 & -0.102 & -0.024 & -0.117 & -1.307 & -0.058 \\
\hline & $(0.488)$ & $(0.489)$ & $(0.510)$ & $(0.488)$ & $(0.596)$ & $(0.244)$ \\
\hline \multirow[b]{2}{*}{$y_{i t}$} & 2.056 & 1.917 & 2.618 & 2.056 & 2.389 & 2.056 \\
\hline & $(0.414)$ & $(0.406)$ & $(0.421)$ & $(0.414)$ & $(0.431)$ & $(0.414)$ \\
\hline \multirow[b]{2}{*}{$y_{j t}$} & 2.246 & 2.122 & 2.416 & 2.246 & 2.563 & 2.246 \\
\hline & $(0.405)$ & $(0.396)$ & $(0.421)$ & $(0.405)$ & $(0.420)$ & $(0.405)$ \\
\hline \multirow{2}{*}{$S A Y_{i t}$} & -2.377 & -2.384 & 1.779 & -2.377 & -2.474 & -2.377 \\
\hline & $(0.272)$ & $(0.278)$ & $(0.547)$ & $(0.272)$ & $(0.271)$ & $(0.272)$ \\
\hline \multirow{2}{*}{$S A Y_{j t}$} & 2.583 & 2.624 & 0.951 & 2.583 & 2.719 & 2.583 \\
\hline & $(0.278)$ & $(0.280)$ & $(0.548)$ & $(0.278)$ & $(0.280)$ & $(0.278)$ \\
\hline \multirow{2}{*}{ land $_{i t}$} & -0.640 & -0.712 & -0.136 & -0.640 & -0.640 & -0.640 \\
\hline & $(0.232)$ & $(0.231)$ & $(0.280)$ & $(0.232)$ & $(0.229)$ & $(0.232)$ \\
\hline \multirow{2}{*}{ land $_{j t}$} & 0.917 & 0.976 & 1.010 & 0.917 & 0.903 & 0.917 \\
\hline & $(0.269)$ & $(0.267)$ & $(0.280)$ & $(0.269)$ & $(0.266)$ & $(0.269)$ \\
\hline \multirow{2}{*}{$d e n_{i t}$} & -1.475 & -1.523 & -1.854 & -1.475 & -1.814 & -1.475 \\
\hline & $(0.382)$ & $(0.386)$ & $(0.403)$ & $(0.382)$ & $(0.398)$ & $(0.382)$ \\
\hline \multirow{2}{*}{$d e n_{j t}$} & -1.918 & -1.974 & -2.122 & -1.918 & -2.268 & -1.918 \\
\hline & $(0.388)$ & $(0.386)$ & $(0.403)$ & $(0.388)$ & $(0.404)$ & (0.388) \\
\hline \multirow{2}{*}{$B_{i j t}$} & -1.942 & -1.951 & -2.033 & -1.918 & -2.721 & -1.942 \\
\hline & $(0.237)$ & $(0.240)$ & $(0.247)$ & $(0.321)$ & $(0.363)$ & $(0.237)$ \\
\hline $\mathrm{R}^{2}$ & 0.705 & 0.745 & 0.681 & 0.707 & 0.714 & 0.705 \\
\hline D.W. & 1.181 & 1.190 & 1.111 & 1.176 & 1.190 & 1.181 \\
\hline
\end{tabular}

It can be found that the coefficients of the same parameter do not differ too much in each year, indicating that this revised model is well-organized. To look closely, we can see that the last method using squared distance tends to share the same results with the regular regression except the coefficients of the distance are cut half. The result of method (5) shows a greater difference than that of the rest, probably because of the wrong assumption of the distance calculation in NL method, the assumption that the customers are randomly distributed in a round circle.

The signs and the magnitudes of the coefficients in all sample years are in line with most estimates of the impact of distance and economic size on agricultural trade found in the literature: Imports of agricultural products are negatively affected by the distance between the trading pairs and positively affected by the size of their economies. Five distance coefficients tend to decrease in absolute value, showing the decline of the effect of distance on bilateral trade. The agricultural GDP or GDP of both importers and exporters positively affect the bilateral trade. The estimates also show that the bilateral trade seems to be positively affected a little more by the economy of the importer than by that of the exporter, probably reflecting the fact that the agricultural demand has a greater influence in the market. In addition, a higher share of agricultural product in GDP is related to higher exports of agricultural goods as expected and a higher share of agricultural product in 
GDP tends to result lower imports of agricultural goods. The quantity of agricultural products a region imports seems to be inversely related to its land area. But land area of the exporting region is not found consistent in both specifications. Maybe it's because the greater land area of the exporting region might be due to its own great demand in agricultural products. Rural population density is also found to be inversely related to the bilateral trade. The greater number of the farms in one region results in more demands of agricultural products, so less trade is resulted.

Finally, all dummies in five tables are below zero indicating that border creates an invisible barrier to bilateral agricultural trade and that China-US agricultural trade is also possibly influenced by the other trade partners in the world. The regression results of equation (2) using the same six methods show similar results and are omitted here for space consideration.

\subsubsection{The magnitude and evolution of border effects}

Border effects of each year can be calculated from the anti-log of the dummy coefficients. The evolution of the bilateral border effects, the China export border effect to US and China import border effect from US are better seen in Fig. 1 to Fig. 3 respectively.

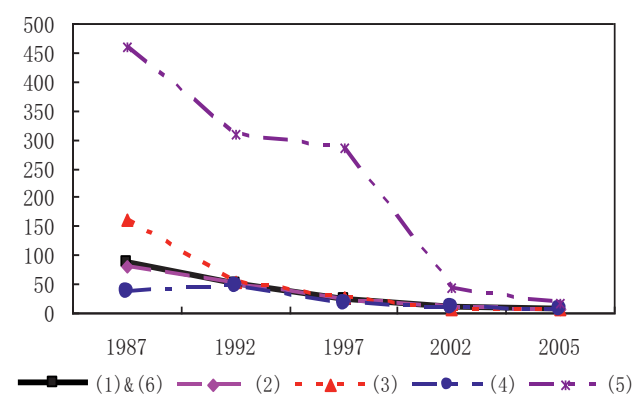

Fig. 1: China-US border effect over time

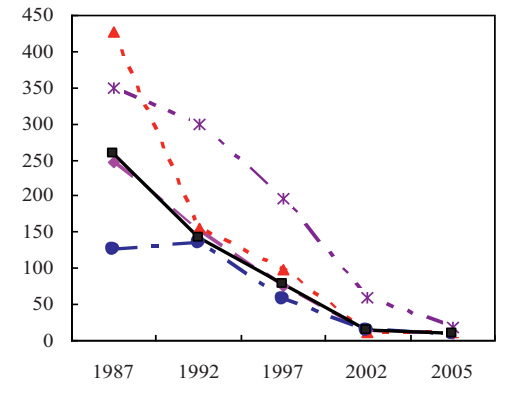

Fig. 2: China $\rightarrow$ US border effect

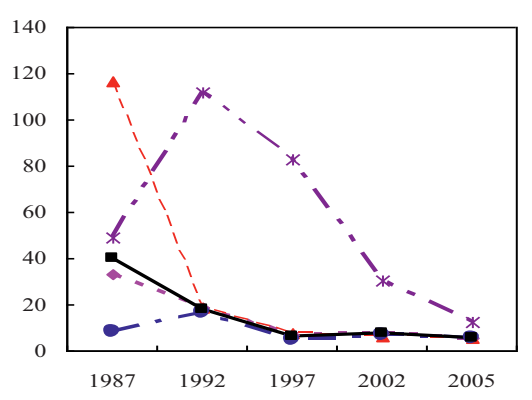

Fig. 3: US $\rightarrow$ China border effect

First, the estimation of equation (1) using six methods all indicate the great magnitude of China-US border effects in agricultural trade. The border 
effects without considering the direction of the trade range from 36 to 160 in 1987 and drop quickly to $7-15$ in 2005 with the exception of method (5). In average, this means one Chinese region tends to trade agricultural products around 87 times more with another Chinese region than with an identical US region in 1987. In 2005 it drops to 7. Different methods of distance calculation only affect the border effect of data 1987, while all the other methods except method (5) show a similar magnitude of border effect over 1992-2005. The third method using total economy development named GDP tends to overestimate border effect while Wei's method tends to underestimate it.

Second, border effects are also significant in value with the decreasing trend when the direction of trade is taken into consideration. Also method (5) shows a different result. On the one hand, the Chinese agricultural export border effects to US are amazingly large in value, ranging from 426 to 125 in 1987 and from year 1992 it drops quickly from 142 to 9 in year 2005 in average. This shows that more Chinese agricultural products have been exported to US than to the other Chinese regions due to the government's new policy in agriculture. On the other hand, the Chinese agricultural import border effects from US remain comparatively stable ranging only from 6 to 40 during the two decades. The smaller magnitudes of the import effect than the export effect shows that in the international agricultural market with US, Chinese regions import more agricultural products from US than from other domestic regions, but export more to domestic regions than to US. This fact leads to Chinese large deficit in agricultural trade with US.

\section{CONCLUSION}

This paper tries to explore the border effects of China-US agricultural trade based on the Gravity Model. Two models are put forward and six methods are used to make an empirical study on the magnitudes, evolution of the border effects and on the relationship of variables involved in the model applying the panel data covering 1987-2005. Results indicated that the main determinants of trade in a gravity framework- economic size and distance-have the same influence on agricultural trade as they have on total merchandise trade. As for new variables specific to agricultural trade, the estimates show that a higher share of agriculture in GDP and a lower rural population density are associated with higher bilateral trade flows of agricultural products. Distance variable tends to have a decreasing negative influence on bilateral agricultural trade, indicating the fewer barriers to the trade. Logarithmic linear equations can explain the border effects of ChinaUS agricultural trade. The method of using total economy development tends 
to overestimate all border effects of China-US agricultural trade while Wei's method of calculating distance tends to underestimate them.

The border effects of China-US agricultural trade are significantly large no mater whether the direction of trade is considered. The impact of borders on both sides has declined over time. It is found that the Chinese import border effect in agricultural trade is more stable and smaller than its export border effect to US. China needs to establish appropriate policies to promote China's agricultural trade to US to ease the burden of deficit in this area.

\section{ACKNOWLEDGEMENTS}

Funding for this research was provided by National Natural Science Foundation of China under grant 70473057. The first author is grateful to the Shanghai Maritime University for providing her with pursuing a $\mathrm{PhD}$ degree at the Shanghai Jiao Tong University.

\section{REFERENCES}

A. Olper, V. Raimondi. Access to OECD agricultural market: a gravity border effect approach, in the 99th seminar of the EAAE (European Association of Agricultural Economists), 2005, 24-27

C. Paiva. Assessing protectionism and subsidies in agriculture: a gravity approach, IMF working paper, 2005, no. 21

C.L. Evans. The economic significance of national border effects, American Economic Review, 2003, 93(4): 1291-1312

Center of National Information of China. Multi-Regional Input-Output Model for China, Beijing: Publishing House of Social Science and Literature, 2005 (in Chinese)

E. Leamer. Access to western markets, and eastern effort levels. in S. Zecchini, Lessons from the Economic Transition: Central and Eastern European the 1990s, Dor-drecht; Boston: Kluwer Academic Publishers, 1997

J. E. Anderson, E. V. van Wincoop. Gravity with gravitas: a solution to the border puzzle, The American Economic Review, 2003, 93: 170-192

J. McCallum. National borders matter: Canada-U.S. regional trade patterns, American Economic Review, 1995, 85(3) 615-623

K. Head, T. Mayer. Non-Europe: the magnitude and causes of market fragmentation in the EU, Weltwirtschaftliches Archive, 2000, 136(2): 285-314

Shicunzhenyi, Wang Huijing. Interregional Input-Output Analysis of the Chinese Economy, Beijing: Publishing House of Chemical Industry, 2007 (in Chinese)

V. Nitsch. National borders and international trade: evidence from European Union, Canadian Journal of Economics, 2000, 22: 1091-1105

W. H. Furtan, M. Blain. van Melle. Canada's agricultural trade in north America: do national borders matter?, Review of Agricultural Economics, 2004, 26(3): 317-331

Wei Shangjin. Intra-national versus international trade: how stubborn are nations in global integration?, NBER Working Paper, 1996, no. 5531 